\title{
Education and transition to work among youth in Tamil Nadu
}

International Institute for Population Sciences (IIPS)

Population Council

Follow this and additional works at: https://knowledgecommons.popcouncil.org/departments_sbsr-pgy

Part of the Demography, Population, and Ecology Commons, Education Commons, Family, Life Course, and Society Commons, International Public Health Commons, and the Medicine and Health Commons How does access to this work benefit you? Let us know!

\section{Recommended Citation}

International Institute for Population Sciences (IIPS) and Population Council. 2009. "Education and transition to work among youth in Tamil Nadu," Youth in India: Situation and Needs Policy Brief no. 13. Mumbai: IIPS. 


\section{Education and transition to work among youth in Tamil Nadu}

The extent to which India will be able to successfully harness its demographic dividend depends significantly on the situation of its youth, notably on the levels of education and marketoriented skills they attain. In many states, youth have indeed made progress on these fronts. Youth in Tamil Nadu, for example, have made considerable strides in terms of educational attainment. The vast majority of youth (over $90 \%$ ) have attained at least 5 years of schooling; and irrespective of sex, youth have attained a median of 9-10 years of schooling. Yet it is not clear that youth in Tamil Nadu are prepared for the challenges they will face in a globalised world. For example, are opportunities available to youth that enable them to complete secondary education, increasingly a prerequisite for participating in the labour market in the context of globalisation? ${ }^{\text {a b }}$ Likewise, are opportunities available that enable youth to overcome skill mismatches through vocational skills and training? Are youth in Tamil Nadu succeeding in finding productive employment and becoming integrated into the labour market? Are they transitioning into work roles at appropriate ages and with adequate skills? Also, given that the achievement of the demographic dividend rests to a considerable extent on the expected rise in work participation of women, are opportunities available for young women to make the most of their productive potential?

Looking at the current educational and employment situation of youth in Tamil Nadu, this policy brief argues that significant investments in terms of appropriate policies and programmes are required to enable the state to harness its demographic dividend and its youth to participate in and benefit from global development.

The study

The Youth in India: Situation and Needs study is a sub-nationally representative study undertaken for the first time in India of key transitions experienced by young people in six states of India, including Tamil Nadu. The study included a representative survey of young people in both rural and urban settings. Respondents included unmarried women and men and married women aged 15-24 and, in view of the paucity of married men in these ages, married men aged 15-29.

In Tamil Nadu, the survey was conducted in 2006-07. A total of 7,996 married and unmarried young women and men were interviewed in the survey. These included 1,322 married young men, 1,666 unmarried young men, 2,007 married young women and 3,001 unmarried young women. This brief is based on data obtained from 1,913 young men and 5,008 young women aged 15-24.

\section{Secondary school completion is far from universal}

Although the state government has introduced several incentives schemes to achieve universal secondary education, findings from the Youth Study indicate that secondary school completion was far from universal; just $51 \%$ of young men and $48 \%$ of young women had completed 10 or more years of schooling. Even among the younger cohort (aged $15-19)$, just over half of young men (55\%) and young women $(53 \%)$ had completed secondary school. Findings, moreover, suggest that married youth were less likely than the unmarried $(28 \%$ versus 55\% among young men and 32\% versus $58 \%$ among young women), and rural youth were less likely than the urban $(46 \%$ versus $57 \%$ among young men and $41 \%$ versus $57 \%$ among young women) to have completed secondary school.

Of note is the striking difference in the proportion of young people who had completed 10 or more years of schooling by economic status of young people's households, as measured by wealth quintiles (with the first quintile representing households of the lowest wealth status and the fifth quintile representing households with the highest wealth status). Differences by economic status were much wider than differences by gender, marital status or rural-urban residence. For example, among young men and women, just one-quarter of those from households in the poorest quintile had completed 10 or more years of schooling, compared to four-fifths of those from households in the wealthiest quintile.

A number of factors inhibited secondary school completion. Leading among these were economic

a United Nations. 2007. Goals and targets for monitoring the progress of youth in the global economy: Report of the Secretary-General, New York, United Nations.

b National Research Council and Institute of Medicine. 2005. Growing up Global: The Changing Transitions to Adulthood in Developing Countries, Washington, D.C.: The National Academies Press. 
Percentage of young people who had completed secondary school, according to household economic status

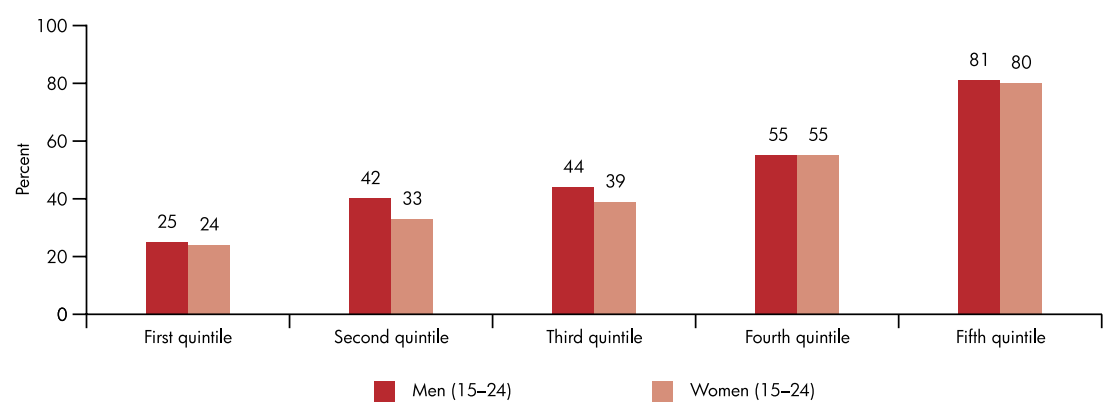

reasons, attitudes and perceptions of youth, and school-related reasons. For example, $67 \%$ and $43 \%$ of young men and women, respectively, who had discontinued schooling after completing Class 7 and before completing Class 10 reported that they had left school for economic reasons (work on the family farm or business, wage earning work, family poverty, i.e., the family could not afford to keep them in school). School-related reasons, particularly academic failure and poor school quality, also accounted for discontinuation among large percentages of young men and women $(47 \%$ and $51 \%$, respectively). Notably, $36 \%$ of young men and $32 \%$ of young women reported academic failure as a reason for school discontinuation. Young people's own lack of interest in schooling was cited by over half of young men and almost one-third of young women as a reason for school discontinuation. Housework-related reasons and factors relating to the transition to adult roles, including marriage and employment, were reported by relatively few youth.
Moreover, findings show that the kind of training received varied by the sex of the respondent. Among young men who had received vocational training, leading training programmes reported were focused on computer skills (53\%), English language, typing or shorthand (17\%), driving $(15 \%)$ and auto mechanics (14\%). Although training in computer skills and English language, typing or shorthand were reported by considerable proportions of young women as well (39\% and $22 \%$, respectively), training in traditional skills dominated among them. For example, 54\% of those who had received any vocational skills training reported training in tailoring.

Findings also show that large proportions of youth- $43 \%$ of young men and $53 \%$ of young women-were interested in acquiring vocational skills. Notably, both young men and women expressed an interest in receiving training in computer skills and English language, typing or

Reasons for school discontinuation among those who had discontinued their education after completing Class 7 and before completing Class 10

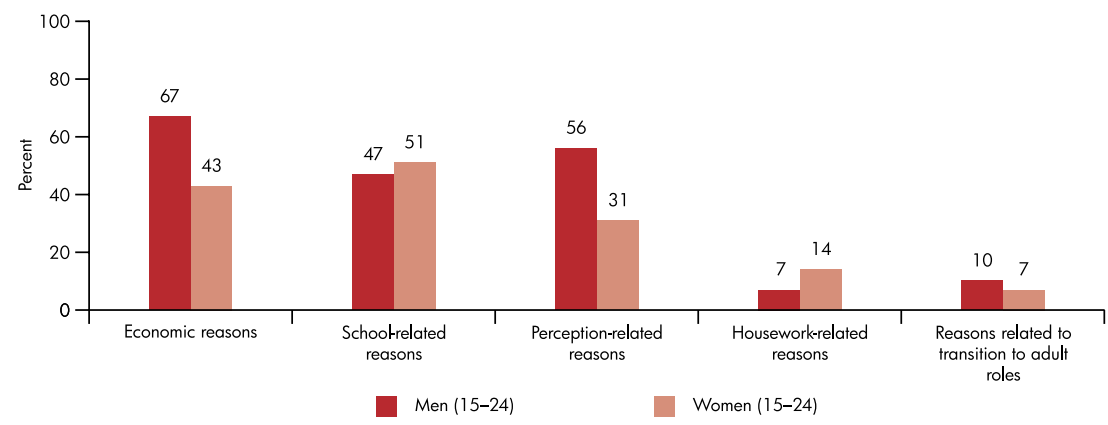

Many had not acquired vocational skills A number of vocational training programmes are available to youth through government, nongovernment and private organisations. However, findings indicate that just $25 \%$ of young men and $32 \%$ of young women had ever availed of the opportunity to attend a vocational training programme. shorthand. A majority of young women, moreover, continued to opt for relatively traditional vocational skills as well.

The transition to work roles was not easy or successful for many

Work profiles of young people suggest that the majority of young men (59\% of the unmarried and

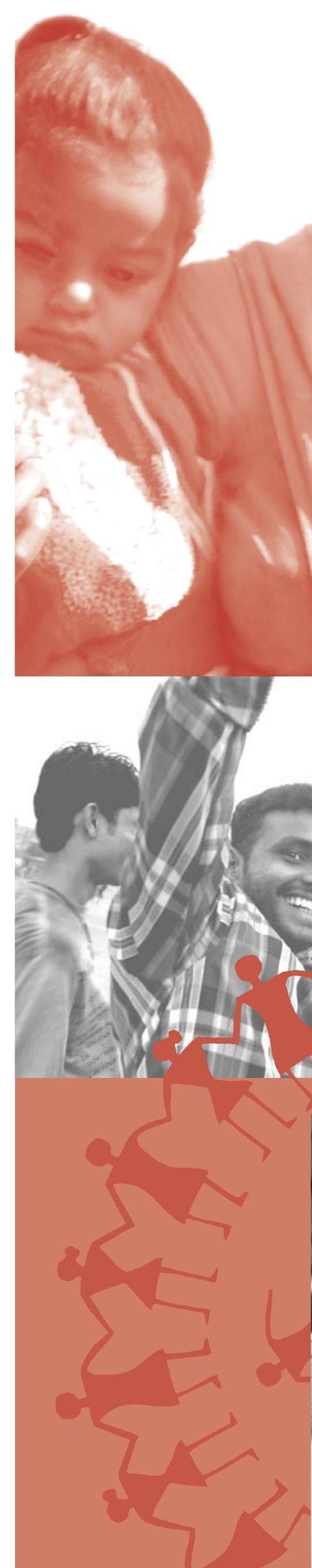


$100 \%$ of the married) and a substantial proportion of young women (37\% and $29 \%$, respectively) had engaged in paid or unpaid work at some point in the 12 months preceding the interview. Findings, however, highlight that the transition to work roles was fraught with challenges.

Sizeable numbers transitioned to work roles at young ages

Despite global recognition that entry into the labour market at young ages competes with young people's schooling opportunities and experiences directly or indirectly, and compromises their productive potential and health, ${ }^{\mathrm{b}}$ and despite significant policy and programme attention to prevent early entry into the labour market in India, ${ }^{\mathrm{c}}$ findings indicate that sizeable proportions of young people had transitioned to work roles at young ages. Indeed, one in five $(21 \%)$ young men and one in six young women (17\%) reported that they had initiated either paid or unpaid work before age 15 .

\section{Considerable proportions of educated young people} were unemployed

Although unemployment rates were by and large low among young people, particularly among young men (7\% of young men and $15 \%$ of young women) in the state, ${ }^{1}$ better educated youth were more likely than others to report unemployment, possibly because of the disconnect between youth skills and market needs. Almost one-fifth of young men and one-third of young women who had completed Class 12 were unemployed, suggesting that the paucity of opportunities limits the ability of even better qualified youth to obtain employment.

\section{Many young women were neither in school nor working \\ Findings suggest that large proportions of young men and women were either in school or working at the time of the interview and a few were both working and studying. However, findings also show that the labour potential of young women was considerably under-utilised. For example, more than two in five young women were neither in school nor working, compared to just $5 \%$ of young men.}

\section{Programme recommendations}

Findings indicate that several challenges remain in ensuring universal access to secondary education and absorbing an increasingly youthful labour force, and thereby harnessing Tamil Nadu's demographic dividend. A number of policies and programmes are needed to overcome these challenges.

Unemployment rate among youth, according to residence and years of schooling

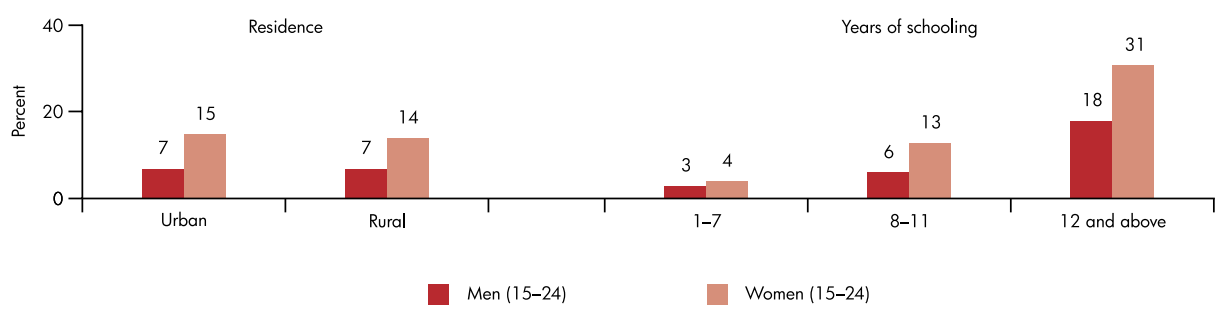

Economic activity and schooling status among young people

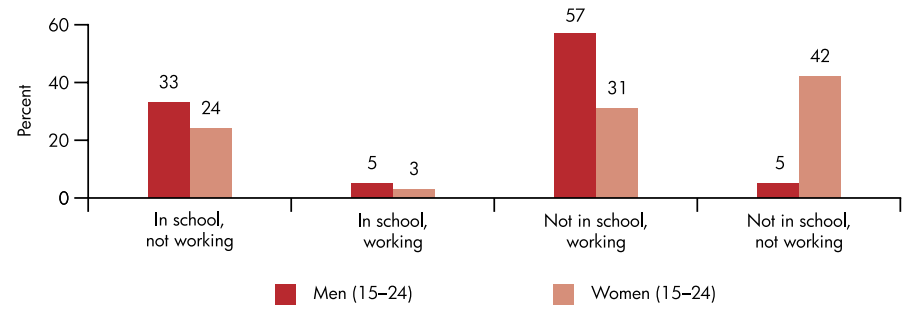

c Ministry of Labour and Employment. 1986. The Child Labour (Prohibition and Regulation) Act 1986, New Delhi: Government of India.

${ }^{1}$ To measure unemployment rates among respondents, the Youth Study assessed (a) whether youth had worked in the 12 months preceding the interview and if so, the number of months worked; and (b) whether youth were seeking work and if so, the number of months during which they had been searching for work. The unemployment rate is calculated as those seeking employment for the major part of the year preceding the interview as a fraction of those who were working or seeking work for the major part of the year, i.e., those in the labour force. 
Make high school completion a priority: provide conditional grants and targeted subsidies

Although young people in Tamil Nadu spend much of their adolescence pursuing their education and the state government has increased investment to promote universal access to secondary education, economic pressures continue to lead parents to withdraw their children from school in favour of work. Indeed, considerable proportions of youth had initiated work in childhood. Conditional grants and targeted subsidies that encourage school completion among disadvantaged groups need to be considered, which would encourage parents to opt for schooling over work for their children. The state government has launched various incentive schemes to address economic pressures; however, it is important that the effectiveness of these schemes is evaluated and promising lessons are assimilated and scaled up.

\section{Raise young people's aspirations regarding education}

Many youth reported lack of interest as a reason for discontinuing their education. Activities directed at young people and their parents are needed that promote positive attitudes towards secondary school completion. Facilities for counselling and follow-up of those considering discontinuation and those who do not return to school must be established and community leaders entrusted with the task of ensuring the completion of a high school education by all youth.

\section{Address school-related barriers}

Activities must also address school-level barriers, notably, poor quality of education and academic failure. Investments in improving the quality of the schooling experience are needed that focus on providing better training of teachers and ensuring greater accountability among teachers. The fact that many youth reported academic failure as a reason for discontinuation reiterate this need and call, in addition, for attention to support students who perform poorly. Finally, efforts are needed that enliven the classroom. The state government proposes to introduce a number of schemes, including the introduction of computer-aided language and mathematics laboratories and these kinds of innovations may serve not only to provide better quality education to youth but also to make learning more enjoyable.

\section{Provide a second chance to continue schooling for those left behind}

Findings that married youth remain considerably disadvantaged in terms of educational attainment levels call for interventions that give the married a second chance to continue their education. Likewise, evidence that rural youth were more disadvantaged with regard to educational opportunities than their urban counterparts calls for efforts to provide those out of school an opportunity to complete their schooling.

\section{Invest in skill acquisition for youth}

Findings show that considerable proportions of youth, particularly educated youth, were unemployed at the time of interview. Formal mechanisms need to be developed that enable youth to acquire skills for which there is an established market demand, and that link them to market opportunities. There is a need, for example, to incorporate livelihood skills building models within the school setting in order to provide opportunities for those in school to gain market-driven job skills that will also expand young people's aspirations regarding their education and careers. There is also a need for skill acquisition forums for other groups of youth, for example, those out-of-school and also the well-educated, among whom unemployment levels are high. As mentioned earlier, the state government has planned to introduce computer-aided language and mathematics laboratories in educational facilities. What is needed is a strong commitment to ensuring that these and other programmes do indeed get implemented effectively and reach young people. 